\title{
TRILHAS FEMININAS: LEVES PEGADAS AO RITMO DA EXPROPRIAÇÃO NO CONTEXTO DO ALTO VALE DO JEQUITINHONHA MINEIRO
}

\author{
WOMEN TRAILS: MILD FOOTPRINTSAFTER THE \\ EXPROPRIATION RHYTHM IN THE JEQUITINHONHA \\ VALLEY CONTEXT
}

\section{Roberta Alves Silva}

alvesroberta81@gmail.com

Graduada em Licenciatura em Educação Do Campo: Ciências da Natureza pela Universidade Federal dos Vales do Jequitinhonha e Mucuri - UFVJM/MG.

Mestranda do programa Interdisciplinar de Estudos Rurais pela Universidade Federal dos Vales do Jequitinhonha e Mucuri - UFVJM/MG.

ORCID: https://orcid.org/0000-0002-7479-7193

\section{Rafael Pereira Santos}

pereirasantosr@yahoo.com.br

Graduado em Pedagogia pela Universidade Federal de Minas Gerais UFMG/MG.

Graduado em Ciências Humanas/Sociais e Linguagens e Códigos pela Universidade Federal dos Vales do Jequitinhonha e Mucuri - UFVJM/MG.

Mestre em Estudos Rurais pela Universidade Federal dos Vales do Jequitinhonha e Mucuri - UFVJM/MG.

ORCID: https://orcid.org/0000-0002-2034-6223

\section{André Rodrigo Rech}

andrerodrigorech@gmail.com

Graduado em Ciências Biológicas pela Universidade Federal da Grande Dourados - UFGD.

Mestre em Biodiversidade: Botânica pelo INPA.

Doutor em Ecologia pela Universidade Estadual de Campinas. Professor na Universidade Federal dos Vales do Jequitinhonha e Mucuri-UFVJM/MG ORCID: https://orcid.org/0000-0003-4685-7483

\section{RESUMO}

A mobilidade humana resulta de vários processos sociais e embora possa ser uma escolha, em muitas situações, ela é impositiva, compulsória e até violenta. Neste sentido, com base nas raízes históricas das mulheres do Vale do Jequitinhonha, o objetivo desse artigo é entender o papel social que a migração - sobretudo a migração feminina - tem tido na estruturação do modo de vida da comunidade Quilombola Monte Alegre, no município de Veredinha, em Minas Gerais. Para tanto, empregamos como metodologia neste processo a pesquisa participante, prezando pela participação efetiva dos sujeitos envolvidos. No decorrer deste trabalho, identificamos quatro formas de deslocamento feminino: a migração permanente com foco nos estudos, a migração para trabalho nas capitais-êxodo rural, a pendular e a sazonal. A migração foi identificada como 
uma forma de resistência da comunidade, mas ao mesmo tempo como um processo de transformação do modo de ser e de viver do povo, sendo o elemento responsável pela desterritorialização e reterritorialização dos comunitários, com a ressignificação social e feminina.

Palavras chave: migração; mulher; ressignificação.

\begin{abstract}
Although it may be a choice, human mobility is a result of complex social processes and may sometimes be unwanted, compulsory and even violent. We framed this study on the historical perspectives ofwomen from the Jequitinhonha valley in order to understand the social role and impacts of migration on the way that traditional communitarians (specially women) are living (or lived) in the Quilombo de Monte Alegre, Veredinha town, Minas Gerais State, Brazil. Quilombos are remnants of Brazilian hinterland settlement founded in the past by people of African originto escape from slavery and resist. This investigation was lead by a communitarian and therefore people engagement in the research was prompted and well appreciated by the authors. Over the investigation process we found four kinds of women migration: study-focused permanent migration, work in large towns permanent migration, pendulum migration to close localities and seasonal migration. Migration clearly emerged from interviews as a community resistance strategy as well as a process of transformation in the way people are and live, being responsible for the process of detachment and re-connection to different territories. Over this process women life was always socially reframed and adapted to the constant changes.
\end{abstract}

Keywords: migration; women; life reframe.

\title{
INTRODUÇÃO
}

O “ir e vir” sempre foi uma característica da porção mineira do Vale Jequitinhonha. As motivações disso são inerentes aos processos de manutenção da vida e da qualidade de vida do povo. Um desses movimentos, o de subir e o descer as chapadas ${ }^{1}$, um constante ir e vir, foi o que garantiu historicamente às comunidades bens naturais e simbólicos nos fazeres da vida. É possível observar também um outro ir e vir, mais reservado e esporádico, do "sertão"2 ou da derriça (colheita) do café capixaba, que garantia, sobretudo aos homens, o recurso maior que necessitavam para a expansão das terras, a compra de gado ou a edificação das moradas. A migração, no segundo caso, é percebida aqui como estratégia de complementação dos meios de existência no território das comunidades. Isso porque toda razão de ir era o que estava por vir em retorno à família e comunidade do trabalhador.

O processo de expropriação da década de 1970, no Vale Jequitinhonha, levou as comunidades a perderem a terra de uso comum (as chapadas) e fez com que os comunitários tivessem seu território limitado às grotas. Esse processo exigiu que fossem criadas novas estratégias de 
sobrevivência para permanência na terra. "O fluxo emigratório se converte em estratégia permanente de sobrevivência. Neste contexto, a saída temporária encerra em si um forte sentido de resistência, uma vez que os recursos que os migrantes remetem à terra de origem, de alguma forma, evitaram a migração definitiva" (FACCIOLI, 1991, p. 9).

Neste contexto brevemente apresentado, forja-se a proposta deste trabalho cujo objetivo é entender o papel social que a migração tem tido na estruturação do modo de vida da comunidade Quilombola Monte Alegre, Veredinha, Minas Gerais, Brasil. Isso, sobretudo com relação à migração feminina, notadamente após o processo de ocupação das chapadas do Vale do Jequitinhonha, a princípio por empresas estatais reflorestadoras.

Este estudo foi desenvolvido no território da comunidade, que está localizada no município de Veredinha no Alto Vale do Jequitinhonha (MG), a $26 \mathrm{~km}$ da sede municipal. Monte Alegre possui fortes traços quilombolas e se autorreconhece formalmente como tal desde o ano de 2018. O reconhecimento se fundamenta na reflexão do modo de ser, estar e fazer (artesanatos, danças, cantos, tradições e memória dos tempos dos escravizados e resquícios da fazenda escravocrata), nos marcos materiais e simbólicos existentes no território (cruzes, cercos de pedra, taperas antigas, utensílios, histórias etc.), nos traços físicos dos comunitários e todos os demais elementos que compõem a identidade do povo. Todavia a comunidade ainda segue no processo de certificação junto à Fundação Palmares.

Atualmente quatorze famílias residem na comunidade e sete são consideradas como público intermitente, pois apesar de ainda manterem vínculos afetivos e de trabalho com o local, geralmente com uma unidade produtiva em funcionamento, não residem integralmente na comunidade. $\mathrm{O}$ modo de vida dos comunitários(as) é vinculado à agricultura tradicional/familiar e seus processos e, também, ao extrativismo de recursos naturais, mantendo uma relação de proximidade, pertencimento e respeito com a natureza. Ao mesmo tempo em que faz um uso aparentemente sustentável dos recursos naturais, a comunidade vive conflitos ambientais e territoriais, advindos ou provocados pelo processo de expropriação (SILVA et al., 2019).

A metodologia utilizada foi a pesquisa participante, uma vez que propomos um trabalho de interação com a comunidade, abordando questões com intensa participação e diálogo com os sujeitos da pesquisa. Uma visita exploratória como proposto por Freire (1999) foi realizada no início da pesquisa, com a finalidade de expor a proposta de investigação e também de apresentar a equipe enquanto pesquisadores para comunidade. Esta visita foi importante, considerando que a primeira autora deste artigo é oriunda da comunidade, o que possibilitou o início de outra forma de envolvimento com os comunitários, agora, enquanto pesquisadora. Compreendemos que a realização do planejamento 
parcial com a comunidade em um processo de construção horizontal é vantajosa por abrir possibilidades e perspectivas antes não observadas. E sobretudo por colocar a comunidade de fato em prática, na condição de sujeitos de ação no processo de pesquisa. Desta forma, enxergamos que a pesquisa e a educação não estão dissociadas, de modo que pesquisar é então um ato educativo, que caminha para a "produção de novos conhecimentos capazes de aumentar a consciência e a capacidade de iniciativa transformadora dos grupos com que trabalhamos" (OLIVEIRA; OLIVEIRA, 1999).

O procedimento metodológico empregado foi a aplicação de dois modelos de questionários semiestruturados, previamente aprovados pela Comitê de Ética em Pesquisa-CEP-UFVJM (parecer 3.464.046). Foram entrevistadas nove mulheres e dois homens, totalizando um montante de onze pessoas. Em síntese, o público entrevistado foi constituído de pessoas que residiam em Monte Alegre e migraram e pessoas que ainda residem na comunidade. A escolha das(os) entrevistadas(os) se deu a partir de indicação das lideranças da comunidade. Todas(os) as(os) entrevistadas(os) possuem mais de 40 anos e aceitaram contribuir de forma livre, espontânea e esclarecida. As entrevistas, embora tenham sido orientadas por um roteiro, foram conduzidas como um diálogo entre pesquisando e pesquisados. Cada uma das entrevistas teve duração entre quarenta minutos a uma hora e ocorreram na casa dos entrevistados.

\section{AS “RAÍZES” DAS MULHERES DE MONTE ALEGRE}

Desde as sociedades antigas, o trabalho doméstico e dos arredores já tinha caráter feminino, enquanto a busca por alimentos (sobretudo a caça) ficava a cargo dos homens. No entanto, as duas frentes de afazeres eram cingidas de um sentido social de coletividade, nos processos de trabalho. Mas com o advento da família patriarcal eurocêntrica, o caráter social que envolvia todas as atividades deixa de existir, fazendo emergir no lugar o caráter privado dos serviços, com funções individuais, tornando a mulher uma criada da casa (NOGUEIRA, 2004). Após a revolução industrial, a mulher se inseriu no mercado de trabalho em função da utilização das máquinas que dispensavam a obrigatoriedade da força física no universo laboral. Elas que antes se limitavam ao trabalho doméstico e à vida familiar, iniciam uma nova fase que aparentava ser de emancipação. Porém, o processo que permitiu de alguma forma o início da emancipação é o mesmo que concede mais força de trabalho ao capitalismo e alimenta outra forma de exploração (NOGUEIRA, 2004).

As mulheres de Monte Alegre (para além das entrevistadas) nasceram no contexto patriarcal posterior ao período escravocrata aprendendo e forjando o "ser mulher" neste cenário. A criação da família, que normalmente tendia a ser numerosa, era rígida, segundo o que contam 
as moradoras da comunidade. De acordo com seu Francisco, ex-morador de Monte Alegre, residente em Vendinhas, os filhos só saíam de casa, no sentido de independência, quando se casavam. Até lá, tudo que conquistavam, seja na terra dos pais, no trabalho à meia com vizinhos, ou em casos esporádicos no sertão ou corte de cana, era para família como um todo, tendo inclusive uma obrigação para com os irmãos mais novos.

Eu, na verdade, fiquei até no período que eu fui casar, a relação era um pouco diferente só porque eu morava aqui (Vendinhas), mas eu ia para roça ajudava a cuidar. Eu sempre ajudei meus pais, né, não tinha aquela coisa assim de trabalhar só para mim. Meu pai só me deu liberdade de eu ganhar meu dinheirinho para arrumar meu casamento, quando faltava seis meses para mim casar. Ajudava porque eles não tinham condição, né! Muitas pessoas hoje pensam diferente, mas nós ajudava, na verdade eu e meu irmão mais velho era como se nos fosse os pais dos meus irmão mais novo. Nós era responsável para comprar onde tivesse e arrumar dinheiro onde tivesse para pagar. Antigamente era assim nas famílias, e no nosso caso era pior porque nosso pai trabalhava mas não conseguia administrar" (Francisco Lopes, 42 anos, comunidade Vendinhas).

No geral, não existia a divisão do trabalho, tudo o que poderia ser atribuído ao homem era também atribuído às mulheres, no entanto existia o trabalho doméstico, e este sim era atribuído somente às mulheres. "No que tange às mulheres não há uma dicotomização da jornada de trabalho. O que existe é uma imbricação das diferentes atividades exercidas" (SILVA, 1991, p. 41). Silva (1991) usa a expressão Jornada justaposta para definir a situação do trabalho, considerando que o termo "dupla jornada" é empregado no sentido de relações salariais capitalistas.

As mulheres faziam de tudo. As mulheres ajudavam a fazer tijolo, teia, e fazia adobe também. Pra construir, fazer a casa, o pai lá em casa tinha muito filho, então os filhos iam casar e tinha que fazer a casa no terreno, né. Então a gente tinha que ir lá e ajudar, onde tinha aquele barro a gente ia fazer [os tijolos e telhas]. Eu tinha cinco anos de idade e dava conta de desenformar os tijolo tudo para es ir colocando mais" (Geni Nunes, 42 anos, comunidade Vendinhas).

Eu acho que tudo que o homem faz mulher pode fazer. Todos fazia junto. Só o serviço da casa que é só da mulher" (Ana Alves, 62 anos, comunidade Vendinhas).

Por volta do período de 1980, enquanto para o homem era comum sair de casa para "tentar a sorte", com o objetivo de conquistar o que lhe faltava para um casamento (casa, terra em alguns casos, gado etc.), para a mulher era comum fazer com suas mãos o que serviria de utensílios em sua casa, seja panelas, esteira ${ }^{3}$, cobertores, guardanapos ${ }^{4}$, lençóis de cama, roupas, vassouras, sabão etc. As mulheres também ajudavam o 
futuro marido a fazer os adobes e telhas que seriam usados na construção da casa. Os irmãos e pais do homem, futuro esposo, também o ajudavam nesta construção.

A migração não era comum às mulheres. Estas, no máximo trabalhavam a dia para os vizinhos e parentes em suas lavouras, em troca de uma "medidinha do que comer" (Geni Nunes, Monte Alegre). Além disso, a mulher recebia menos do que o homem; se ao homem por um dia de serviço prestado na lavoura lhe era dado uma rapadura, ou uma medida de qualquer alimento, à mulher seria dada meia. A comunidade hoje encara esse trabalho prestado, com essa forma de pagamento, como uma situação análoga ao trabalho escravo, tanto no caso do homem quanto no da mulher.

"Chegou um tempo que a roça já não dava mais. Não tinha como. Era muita gente em casa, a casa que tinha um pé de manga, era a conta da família" (Geni Nunes, Monte Alegre). E já não tinha mais as chapadas para coleta de alimentos, a complementação da renda, e a solta do gado. "Há na verdade, uma relação estreita entre fraqueza da terra e fraqueza da gente" (SILVA, 1991, p. 40). As terras já não produziam como antes porque estavam sendo super utilizadas, e se a vida do povo é totalmente ligada ao chão que pisa e que planta, a fraqueza desse chão se converte na fraqueza do povo (SILVA, 1991). O humano mais uma vez se mostra uma extensão do que é a natureza na qual está inserido.

A migração feminina inicia de maneira ainda tímida, após a década de 1970, com a expropriação das chapadas, mas impulsionada também por vários fatores que se arrastam desde o Brasil colônia. Para entender o porquê da migração, Gonçalves (2001) aponta o que ele chama de "nó", que seriam as amarras, os entraves que conduzem a tal processo, dentre estes nós destacamos três: a concentração das terras e do poder por parte da elite que tende, a partir daí, a determinar os resultantes sociais; as relações de trabalho, que costumeiramente têm o trabalho escravo como pano de fundo; e a estiagem semiárida cujas consequências têm se intensificado nos últimos anos. "Porém, não podemos cair na ingenuidade de que a seca é fator predominante da saída em massa do Nordeste e de Minas Gerais. A seca apenas agrava uma situação fundiária já extremamente desigual. Mais que a seca, o que expulsa... é a cerca" que limita (GONÇALVES, 2001, p. 180).

Nesse contexto, "as pessoas migram porque na sociedade de origem já não há lugar para elas, de onde desapareceram as condições para continuarem sendo o que sempre foram, o que estavam acostumadas a ser" (MARTINS, 2018, p. 15). O migrar temporário, nesta nossa interpretação, é a maneira encontrada, que possibilita a comunidade e a família continuarem a ser, ainda que o processo modifique esse ser incorporando as ausências. Percebemos que é tirado das famílias o direito de ir e vir, quando lhes é, de certo modo, imposta a migração, porque o direito de ir e vir consiste também no direito que escolher por ficar (GON- 
ÇALVES, 2001, p. 174). No caso dos homens, a migração já existente se intensificou ao longo do tempo. Já no caso das mulheres, ao longo do tempo podem ser identificadas respectivamente quatro formas de migração que foram surgindo: 1) a migração para estudar, que acaba por se converter em migração permanente; 2) a migração para as capitais, no processo de êxodo rural a procura de emprego; 3 ) a migração para os arredores da comunidade; 4) e a migração sazonal para a colheita de café.

\section{AS TRILHAS DAS MULHERES EM MOVIMENTO}

As primeiras mulheres a deixar a comunidade, sozinhas e ainda solteiras, saíram em busca de oportunidade de estudos, o que não era comum na época, considerando que para que as filhas estudassem, os pais deveriam ter condições financeiras para mantê-las distante de casa. O destino destas mulheres era geralmente as cidades próximas, onde conseguiam abrigo na casa de algum parente ou até mesmo algum desconhecido que as aceitava como domésticas para que estudassem. Em raros casos elas regressavam para a comunidade. Isso porque passava a existir pouca compatibilidade entre o que almejavam e o que a comunidade tinha a oferecer. O resultado era a migração permanente para cidades grandes, à procura de trabalho, na esperança de continuarem a estudar.

Por isso pode-se dizer que a migração temporária deixa marcas permanentes. $\mathrm{O}$ retorno periódico ao ponto de partida não constitui a identidade original nem as relações sociais originais do trabalhador. A migração não é estranha a esse pequeno mundo de origem: altera-o, modifica-o de tal modo que ao retornar o migrante já não encontra a mesma situação que deixara. Sua ausência modifica o arranjo de suas relações sociais (MARTINS, 1991, p. 30).

Dona Tereza foi a primeira moça que, após sair e estudar, regressou para a comunidade como professora do lugar, revolucionando de certo modo o local. A geração de Monte Alegre que hoje se encontra com cerca de 40 anos foi a primeira geração da comunidade a ser alfabetizada, o que mudou os horizontes da comunidade. Além dos feitos na educação, dona Tereza ganhou um destaque social e passou em muitos momentos a ser uma das representantes sociais da comunidade frente às organizações municipais sobretudo as religiosas. Esse lugar de liderança era até então impensável para uma mulher, sobretudo no contexto da comunidade.

Quando eu comecei a estudar, eu comecei já mais velha, assim, depois dos meus 10 anos. Aí eu fiz em Macaúbas de $1^{\circ}$ a $3^{\circ}$ série, era minha comunidade. Depois da $3^{\circ}$ série, eu fui para Turmalina para concluir até a $4^{\text {o }}$ série, fiquei morando em Turmalina um ano, estudando lá. Dificuldade, né! Porque a gente nunca tinha saído de casa, né! Mas graças a Deus 
deu tudo certo. Aí eu consegui até a 4 série, aí depois da quarta série eu vim para roça de novo. Ai, eu comecei a dar aula em Monte Alegre, dei aula lá um ano e lá mesmo eu me casei. Aí apareceu um estudo em Couto Magalhães, um estudo a distância, a gente só ficava lá durante as férias, né! Férias de janeiro a gente ficava 15 dias, férias de julho 15 dias, e aí fiquei lá por 2 anos estudando, ia e voltava. Não foi brinquedo, foi muito difícil para mim, mas a gente sempre com aquele esforço, né! Saia de casa durante esses 15 dias, deixa as crianças em casa, o marido, e saia para dar aula também" (Tereza Cordeiro dos Santos, 66 anos, comunidade quilombola Monte Alegre).

Neste mesmo período, a partir de 1990, a migração feminina, quase inexistente, torna-se frequente no sentido dos grandes centros (Belo Horizonte, Uberlândia, Nova Serrana), em busca de oportunidades de trabalho. As moças saíam à procura de emprego como domésticas nas casas de famílias. Essa movimentação grande de pessoas configura o êxodo rural na comunidade porque estas moças não regressam mais, elas vão no intuito de permanecer. Segundo Sayad (1998), a forma de interpretar a migração/ imigração, oscila entre duas vertentes: se por um lado é vista como provisória, pelo direito do migrante, por outro ela é vista como uma situação duradoura, a interpretar pelos fatos. $\mathrm{O}$ autor diz que existe entre a população a necessidade de confessar a migração como provisória, justamente para não admitir que cada vez mais ela tem se tornado permanente. Os próprios migrantes preferem ver sob essa óptica, e essa seria algo como uma condição para que a migração/ imigração continuasse a existir.

Por se encontrar dividida entre essas duas representações contraditórias que procura contradizer, tudo acontece como se a imigração necessitasse, para poder se perpetuar e se reproduzir, ignorar a si mesma (ou fazer de conta que se ignora) e ser ignorada enquanto provisória e ao mesmo tempo não se confessar enquanto transplante definitivo. Da mesma forma como que se impõe a todos, essa contradição fundamental, que parece ser continuativa da própria condição do imigrante, impõe a todos a manutenção da ilusão coletiva de um estado que não é nem provisório nem permanente, ou, o que dá na mesma, de um estado que só é admitido hora como provisório (de direito), com a condição de que esse "provisório" possa durar indefinidamente, ora como definitivo (de fato), com a condição de que esse "definitivo" jamais seja enunciado como tal (SAYAD, 1998, p. 46).

As mulheres não saíam não, começaram a sair de uns anos para cá. As que saíam era para caçar emprego. Aí iam para mais longe, e iam trabalhar como doméstica. Na nossa região aqui, só saíam para trabalhar como doméstica quando não eram casadas. Lá às vez tinha oportunidade de estudar, estudavam e ia caçar coisa melhor" (Geni Nunes, 42 anos, comunidade de Vendinhas). 
A migração propõe alternativa ao que seria o ambiente de dificuldades, mas em contraposição oferece um ambiente inseguro e cheio de incertezas, o "sair dos grupos sociais permanentes e enraizados" (MARTINS, 2018, p. 13) para um contexto de dessocialização em termos de grupo, afeta quem sai e quem fica.

Durante as entrevistas, o relato de uma dessas mulheres chamou a atenção por narrar o sentimento de voltar à comunidade logo após a migração, nesta mesma perspectiva já narrada. Segundo Maria Ducarmo, sua saída da comunidade se deu muito cedo, aos seus 10 anos. Ela conta que, o regresso foi por um tempo difícil, por encontrar sobretudo na mãe muita resistência a este modo de vida livre, autônomo e distante de casa na condição de solteira. Isso não ocorreu somente com ela, pois estas mulheres que saíam também enfrentavam preconceito por parte de muitos que ficavam, os quais culturalmente viam a mulher em outro lugar. As mulheres, ao migrar, entram em um paradoxo: se por um lado são vistas como aquelas que saíram, por outro lado, lá fora, nem sempre encontraram as melhores condições de trabalho.

As mulheres que saíam, regressavam à comunidade nas férias de final de ano (dezembro a janeiro) ou nos períodos festivos da comunidade, como os meses de maio a julho, com outra perspectiva do ser mulher. Ao receber de volta estas mulheres a comunidade se transforma de alguma maneira, a partir do contato com novos costumes sobretudo no que diz respeito comportamento social feminino, a artigos de beleza, vestuário etc. As que saem da comunidade acabam por entrar na lógica do não lugar, sem um espaço de reconhecimento de si com vinculação identitária (MARTINS, 2018), ou acabam por formar guetos com as iguais dentro das capitais.

O universo urbano, que se estende para além dos limites das cidades, se torna "uma nova mentalidade, uma nova linguagem, um novo jeito de ser - se quisermos, uma nova cultura! O ser urbano é o cidadão do século XXI. Esta cultura não se restringe à geografia da cidade. Por vezes, ela até exerce maior fascínio no campo" (GONÇALVES, 2001, p. 182). Esse contato cultural do campo com as cidades urbanas, que assim nomeamos para diferenciar das cidades rurais ou cidades imaginárias (VEIGA, 2002), se dá em grande medida pela migração de parte da comunidade. Assim a cultura urbana é experimentada pelas pessoas que nunca saíram da comunidade. O que não elimina a cultura tradicional da comunidade, mas a modifica, no processo que Lévi Strauss (1970) chamou de "bricolagem".

Essa migração para cidades maiores não era tão volumosa quanto a que ocorria para os arredores. Muitas mulheres migraram para o povoado de Vendinhas, situado a 2,8 km de Monte Alegre (pertencente aos municípios de Veredinha e Capelinha), ou para cidades próximas à comunidade como Capelinha, Turmalina, Veredinha (Mapa 1). Segundo elas, essa era uma maneira de trabalhar e ao mesmo tempo ainda man- 
ter as atividades antes desenvolvidas na comunidade, principalmente as atividades da lavoura. Esse processo levou à constituição do público que denominamos neste trabalho como intermitente, pelo ir e vir para além da chapada, um ir e vir dividindo o tempo e o espaço da vida.

As moças continuavam a contribuir nos afazeres da casa de seus pais, tudo que era atividade do coletivo elas se faziam presentes. Isso inclui o plantio das roças, a capina, a colheita, a preparação para os pousos do Divino $^{5}$, o calhar ${ }^{6}$ das casas, o arear das vasilhas guardadas, o lavar os cobertores no rio etc. Em tudo que era atividade desenvolvida no coletivo, seja de diversão, de trabalho ou de mobilização social, elas continuaram a participar. Existem também as mulheres que se distanciaram do universo rural e preferiram se manter nas cidades do entorno como doméstica ou trabalhos similares.

A migração aqui descrita é do ambiente rural para outro ambiente também caracterizado como rural em uma mesma região. Apesar de ser uma migração definitiva, isto é, os que migraram têm agora o lugar do destino como local de morada, podemos dizer que eles não deixaram o local de origem, simplesmente o colocaram em outro patamar de vivência. Dessa maneira, a nova relação dos migrantes (já alojados em outro espaço) com a comunidade é agora pendular, eles vão até a comunidade em função do trabalho ou outras atividades e logo regressam às suas casas.

Figura 1 - Mapa de Fluxo da migração feminina na comunidade de Monte Alegre

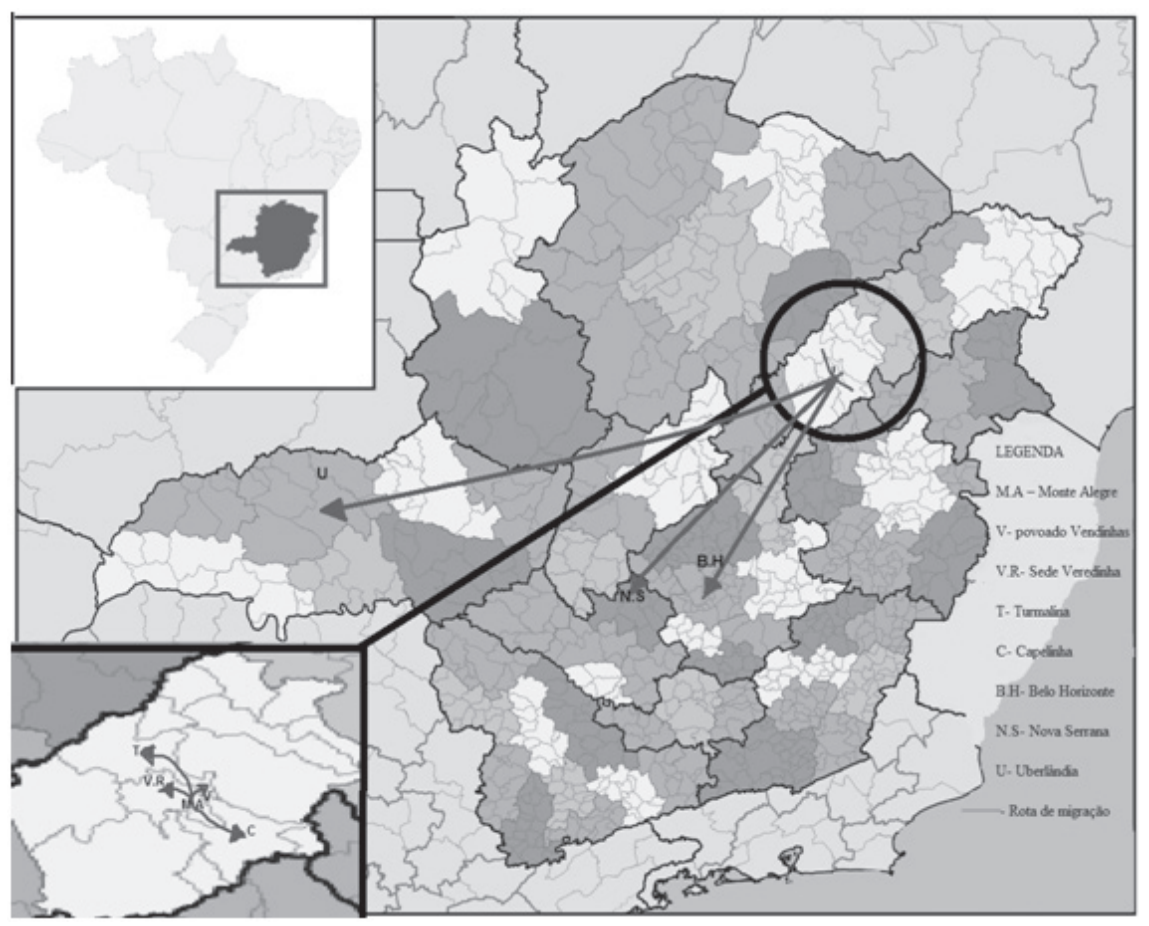

Fonte: $<$ https://www.google.com.br/search?q=mapa+da+microrregi\%C3\%A3o+de+capelinha+mg\&sxsrf=ACYBGNSQXkD7PiBhRzjI1wtfGxQcX> adaptado pelos autores. 
A maior parte da população de Monte Alegre migrou para o povoado de Vendinhas, que fica na área alta, de chapada. É como se a comunidade - ao experimentar os limites impostos de muitas maneiras, tanto econômicos e produtivos, quanto hídricos e sociais - tivesse se recusado a se desfazer. A mudança para Vendinha se tornou uma estratégia para continuar a ser e a pertencer à comunidade. É como se aos poucos toda a comunidade estivesse subindo a Chapada, mas agora para permanecer por lá, mudando de lugar, para se instaurar a $2,8 \mathrm{~km}$ adiante. "A territorialidade é dinâmica e é caracterizada por continuidades e descontinuidades" (SAQUET, 2009, p. 79). Neste sentido, a comunidade territorializada sofre o processo de desterritorialização quando perde as chapadas e depois quando se vê obrigada a sair da grota. No entanto, inicia um processo de reterritorialização e novas relações quando se agrupa no povoado de Vendinhas e mantém suas atividades produtivas e culturais na grota, o lugar de onde veio, que agora se tornou o lugar para onde ir, mantendo-se significado pelo movimento.

Os processos de desterritorialização, segundo Santos (2019), ao refletir sobre o Norte de Minas e Vale do Jequitinhonha, são processos de resistência comunitária que possibilitam inclusive ritos de passagem: casar, buscar estudos fora da comunidade e inclusive buscar acesso a políticas públicas em aglomerados mais densos, conforme sugere Deleuze e Guattari (1995). Santos (2019) afirma que isso implica recorrer a uma ideia de rizoma, termo emprestado da biologia, indicando que no ato de migrar se constitui uma situação nova e não vinculada, necessariamente no seu todo de onde se veio, sem fim, nem início, mas um meio em devir. Assim sendo, eles propõem a noção T-D-R para explicar que todo ato de territorializar implica desterritorializar e necessariamente reterritorializar em um outro lugar. Afinal, todo ser vivente ocupa um lugar no mundo, ainda que seu território seja fluido ou lhe seja negado o direito de territorializar-se nele.

Já a migração sazonal, mais comum às mulheres de Monte Alegre, ocorreu para a derriça do café (março até julho). Todas as mulheres entrevistadas do grupo que residem na comunidade ou que migraram para o povoado de Vendinhas afirmam que iam para a colheita do café ou que ainda vão, sendo esta uma das principais fontes de renda. As fazendas de café ficam no entorno da cidade de Capelinha (região cafeeira). As mulheres saem das casas de madrugada e regressam no entardecer ou no cair da noite, isso no caso das mulheres que residem em Vendinhas. As de Monte Alegre saíam de casa no domingo à tarde e retornavam somente na sexta-feira à noite ou no sábado à noite. Durante a semana ficavam no povoado de Vendinhas, na casa dos parentes que haviam se mudado para o povoado.

Nas fazendas de café o pagamento era de acordo com a quantidade de latas apanhadas, e o acerto era feito no final de cada quinzena. $\mathrm{O}$ recurso, no caso das mulheres solteiras, era destinado a organizar o 
enxoval para o casamento, e a ajudar na casa, se necessário. Quando casadas o recurso era destinado a manter a família, como indicam as falas a seguir.

A primeira vez eu fui pro café foi lá para 85 [1985], eu não era casada não... Eu saí porque precisava de dinheiro. O café mudou minha vida porque aí eu tinha liberdade, eu tinha o dinheiro que eu mesmo ganhava para fazer o que eu quisesse, comprar uma roupa, vasia para casa, um forro de cama diferente. Porque no café a gente ganhava bem, eu ganhava 500 reais por quinzena. Quando eu casei o dinheiro que eu ganhava no café era para despesa da casa, para criar meus filhos e para comer, era pra tudo. Quando eu ia para o café, o meu marido trabalhava, mas era na roça, não era para sair para ganhar dinheiro, mas ajudava. O dinheiro que eu ganhava ajudava acertar os negócios. Era três mês a quatro de safra mas era bão. Na panha [colheita] eu ia à safra toda (Maria de Lourdes, 53 anos, comunidade quilombola Monte Alegre).

Eu comecei a ir para o café em 2005, na época o trem tava feio, o Izé [marido] adoeceu e precisava manter a casa... Mudou porque se eu não ia para o café a gente passava até farta, né! O dinheiro que eu tirava lá era para despesa da casa (Eva Rodrigues, 50 anos, comunidade quilombola Monte Alegre).

Ir para o café era para as mulheres o início da autonomia, tanto financeira quanto do corpo, no sentido de decidir como e onde empregariam sua força de trabalho. O poder de decisão era também o poder sobre o corpo, no sentido de fazer as escolhas dos locais de estar e não estar, os trabalhos a desenvolver sobretudo em casa, estas questões já não eram mais decisões somente dos pais. Esclarecemos, no entanto, que a condição financeira feminina, ou a sua autonomia no sentido mais amplo, não as isentava de sofrer o machismo e as questões a ele atreladas. $\mathrm{O}$ fato é que todo o processo descrito coloca as mulheres em um lugar que antes não se via como possível. Agora não raro as mulheres contam que por um período de tempo eram ou são responsáveis por manter a casa.

No entanto, em boa medida o recurso que se conseguia na colheita do café já se encontrava comprometido com dívidas anteriores, geralmente em torno das despesas de casa, sejam elas alimentos emprestados pelos vizinhos mais próximos, ou em mercearias cujos donos aceitavam anotar as dívidas para pagamento posterior.

Aquela época o povo tinha muito aquele ditado... e realmente, eu vivi, vi muitos viverem, vi meu pai vivendo, eles tinham um dizer de falar "trabalhar cativo". Cativo significa assim, vou trabalhar para você porque eu já te devo. Eu não ia ganhar dinheiro na sua mão, tipo assim eles fala "fulano tá cativo ciclano", ele tava precisando ganhar dinheiro, mas ia trabalhar para pagar a conta primeiro. Meu pai viveu demais, e não foi só meu pai. Muitas e muitas pessoas (Francisco Lopes, 42 anos, comunidade de Vendinhas/Monte Alegre). 
O trabalho cativo obrigou os comunitários a inserção na lógica de trabalho do mercado, porque já não trabalham para si, senão para a pessoa a quem deviam, independentemente de ser este o mesmo que lhe empregava ou não. Sendo assim mesmo que tenham outra necessidade financeira, o recurso é em primeiro lugar destinado a pagar a dívida. Nesse processo, as(os) comunitárias(os) em parte se "alienaram" por se distanciarem dos seus meios de produção à procura da entrada rápida e necessária de recursos através da "venda da mão de obra" (MARX, 1983). Parafraseando Marx, o objeto produzido no processo de trabalho vendido lhes garantia a manutenção de sua existência, e se é então esse objeto que garante seu existir, eles passavam de maneira cruel e ter mais valor do que a própria vida de quem o produziu. No ato de produzir, o trabalhador dá vida ao objeto, então sua vida já não lhe pertence, e ele próprio se torna o objeto de um sistema. Essa natureza humana desfigurada transforma, aos poucos, pessoas em mercadoria (MARX,1983). A leitura que Marx faz do processo de venda da mão de obra retrata, de certa forma, o que acorre nas comunidades de modo geral. Quando os comunitários saem para trabalhar em empresas, perante elas o trabalho do funcionário, a mão de obra dele e os produtos produzidos têm mais valor do que qualquer outra coisa que eles possuam.

No período em que as mulheres estavam no café, os filhos ficavam em casa com os maridos, ou ficavam com os avós, caso o marido também estivesse trabalhando fora. No entanto, em alguns casos, sobretudo quando o marido e a mulher estavam no cafezal, eles costumavam levar os filhos. Ou quando os filhos já eram adolescentes ficavam em casa e cuidavam das criações e da roça, e os avós ou tios somente os monitoravam.

As mulheres que hoje já não vão mais para a colheita do café apresentam sempre dois motivos que conduziram a decisão, o marido se aposentou, e/ou estava com problemas de saúde. Percebemos então que a migração para a comunidade está ligada à necessidade da manutenção do básico e não no sentido de acumulação. Existindo outra opção para manutenção da existência, sair da comunidade não é uma alternativa. Todas as mulheres cujos maridos estão aposentados não saem da comunidade para trabalhar, mesmo que o benefício social ainda esteja aquém da necessidade, já se tem a garantia do básico.

Durante a entrevista, dona Eva, ao ser questionada se acaso na capital lhe fosse garantida melhor oportunidade de trabalho e de renda, se ela se mudaria da comunidade, responde: "Acho que não, uai, largar o meu povo!?"O tom da primeira parte da resposta, "acho que não", demonstra um estranhamento, como algo que não havia lhe ocorrido, seguido de uma resposta com tom de certeza da impossibilidade: "uai, largar o meu povo!". Mudar, sobretudo para longe significa deixar para traz o lugar de vivência e o povo ao qual pertence. 


\section{CONSIDERAÇÕES FINAIS}

A migração, seja ela temporária, permanente, sazonal, pendular, ou qualquer outra classificação conceitual, tende a ressoar em todos os seguimentos da comunidade (econômico, político e, sobretudo, sociocultural). O processo migratório é parte da dinâmica comunitária de Monte Alegre em dois momentos. No primeiro, de forma esporádica e opcional e no segundo de maneira intensa e necessária - em ambos com a possibilidade de dupla avaliação em relação aos impactos na comunidade. Detivemo-nos, nas considerações finais deste trabalho, a sintetizar brevemente os impactos do processo migratório na comunidade de Monte Alegre, com a ênfase no papel feminino.

O sair da comunidade, seja para regressar posteriormente ou para permanecer por lá, foi um movimento de libertação feminina, que deu as mulheres condições de começar a construir sua realização pessoal e intersubjetiva. No que diz respeito aos demais aspectos da comunidade, o êxodo rural e a migração rural-rural fizeram com que se reduzisse em grande medida a população de Monte Alegre, antes numerosa. O que levou também ao envelhecimento da comunidade, considerando que atualmente existem somente duas pessoas com menos de 40 anos dentre os comunitários. Os processos de produção na agricultura foram então reduzidos em virtude do envelhecimento, pois já não se consegue desenvolver a atividade como antes. As relações de produção aos poucos têm sofrido alterações devido a limitações da mão de obra familiar, e da troca de dias entre parentes e vizinhos. Assim, as relações interpessoais de troca e compadrio vão aos poucos se tornado mais difíceis, à medida em que cede lugar às relações contratuais e monetárias que não são comuns ao universo das comunidades tradicionais.

No que diz respeito aos aspectos culturais, muitas atividades deixaram de ser desenvolvidas, como as de produção artesanal. Em alguns casos por perda da matéria prima necessária, em outros, por perda da mão de obra coletiva, ou até mesmo por influência da cultura urbana através da inserção de uma nova lógica de usos e afazeres. Ainda assim, a comunidade tem um cuidado muito especial com os movimentos culturais, que mesmo reduzidos ainda são praticados, porém agora na lógica da nova configuração social.

As folias e pousos do Divino realizadas anualmente em Monte Alegre se adaptaram às novas condições da comunidade. A bandeira do Divino Espírito Santo, que sai anualmente na comunidade de casa em casa no festejo religioso, com a redução das famílias da comunidade, tem mudado sua rota. $\mathrm{O}$ giro agora já não acontece somente dentro da comunidade, vai também para o povoado de Vendinhas ao encontro do povo que, em outro tempo, pertencia a Monte Alegre. Aos poucos o giro do Divino em Vendinhas se torna cada vez mais amplo, em um indicativo de que a cultura da comunidade resiste e vive onde o povo está. 
Vendinhas se configurou um núcleo ativo da comunidade de Monte alegre e também de outras comunidades com história semelhante a ela. Passou a ser um ponto de encontro, de venda/troca de produtos, de investimentos, de articulação política, social e cultural. A alteração da rota do Divino é um marco forte do reconhecimento dos comunitários de que Vendinhas se tornou parte de Monte Alegre. É como se a grota tivesse, pelo menos no plano da utopia, reconquistado uma parcela que lhe foi expropriada na chapada. O vínculo entre vendinhas e Monte Alegre é o exemplo claro da comunidade em movimento. É constituído assim um novo social na comunidade, marcado pelas relações tradicionais, e as novas relações criadas nos universos urbanizados, coexistindo juntas e produzindo a ressignificação cultural, materializada sobretudo no novo espaço, na nova territorialidade e na nova geração que surge.

\section{NOTAS}

1. Subir e descer as chapadas é uma expressão utilizada para representar o modo de vida em trânsito nos dois ambientes (grota: local mais baixo entre águas vertentes, e chapada: parte mais alta e plana). Considerando que a grota é o local de morada onde são construídas as casas e plantadas as roças e as chapada eram áreas de terra coletiva, onde era feito o extrativismo dos frutos do cerrado e a solta do gado.

2. Sertão é como a comunidade denomina os locais para onde os comunitários vão trabalhar cortando lenha, geralmente no Noroeste de Minas Gerais.

3. Esteira é um produto artesanal normalmente fabricado pelas mulheres de Monte Alegre, utilizando a nervura (popularmente conhecida como talo) das folhas seca da bananeira, e a embira da bananeira. Feita na medida das camas, ela é usada embaixo do colchão ou simplesmente para servir de colchão, como antigamente.

4. Guardanapo era o nome dado aos panos menores tecidos com linha e pavio pelas mulheres da comunidade para cobrir copos, pratos ou para embalar doces e quitandas para viagem.

5. O Pouso do Divino ou Giro do Divino é o nome dado à festividade religiosa realizada entre os meses de maio e julho, quando os moradores saem com a bandeira do Divino Espírito Santo pela comunidade, passando de casa em casa, com cantos, orações, folia, caboclo etc. O giro dura nove dias consecutivos, no final de cada dia a bandeira pousa em uma casa, que acolhe ela e o povo que a acompanha com bebida, comida, dança e cantigas até o dia seguinte.

6. Calhar é pintar a casa com cal ou outras tintas feitas artesanalmente a base de tabatinga (argila branca) e terra. Procedimento feito pelas famílias anualmente nas vésperas do pouso do Divino ou no fim do ano.

\section{REFERÊNCIAS}

ALVES, Maria de Lourdes da Silva. Entrevista concedida a Roberta Alves. Veredinha, MG: Gravador, áudio (00:40 h). 16 out. 2019. 
CARVALHO, Eva Rodrigues de. Entrevista concedida a Roberta Alves. Veredinha, MG: Gravador, áudio (00:30 h). 27 jan. 2020.

DELEUZZE, Gilles; GUATTARI, Félix. Mil platôs: Capitalismos e esquizofrenia. Tradução de Aurélio Guerra Neto e Célia Pinto Costa. Rio de Janeiro: Editora 43, 1995.

DORNELAS, Sidnei Marco. Migrações Contemporâneas: desafios para a acolhida e a integração social a partir da pastoral do migrante. Travessia: Revista do Migrante, n. 82, p. 121-144, abr. 2018.

FACCIOLI, Inês. Migrantes Temporários Peregrinos da Resistência. São Paulo: Editora serviço Pastoral dos Migrantes - SPM, 1991.

FREIRE, P. R. Criando métodos de pesquisa alternativa. In: BRANDÃO, C. R. (Org.). Pesquisa Participante. São Paulo: Brasiliense, 1999 GONÇALVES, Alfredo José. Migrações Internas: evoluções e desafios. Estudos Avançados, n. 15, v. 43, 2001.

LÉVI-STRAUSS, Claude. O pensamento selvagem. São Paulo: Editora Nacional e Editora da USP, 1970.

LISTA DE MICRORREGIÕES: Microrregiões de Minas. Disponível em: <https://www.google.com.br/search?q=mapa+da+microrregi\%$\mathrm{C} 3 \% \mathrm{~A} 30+$ de + capelinha + mg\&sxsrf=ACYBGNSQXkD7PiBhRzjI1wtfGxQcX> adaptado pela autora>. Acesso em: 25 jan. 2020.

MARTINS, José de Souza. Migrações Temporárias: problema para quem? In: FACCIOLI, Inês. Migrantes Temporários Peregrinos da Resistência. São Paulo: Editora Serviço Pastoral dos Migrantes-SPM, 1991.

MARTINS, José de Souza. A Sociabilidade do Ausente: drama e libertação nas migrações. Travessia: Revista do Migrante, n. 82, p.11-28, abr. 2018.

MARX, Karl. Manuscritos Econômicos-Filosóficos. In: FROMM, Erich. Conceito Marxista do Homem. 8. ed. Rio de Janeiro: Zahar, 1983.

NOGUEIRA, Claudia Mazzei. A feminização no mundo do trabalho: entre a emancipação e a precarização. Campinas: Autores Associados, 2004.

OLIVEIRA, R. D; OLIVEIRA, M. D. Pesquisa social e ação educativa. In: BRANDÃO, C. R. (Org.). Pesquisa Participante. São Paulo: Brasiliense, 1999.

SANTOS, Francisco Lopes dos. Entrevista concedida a Roberta Alves. Veredinha, MG: Gravador, áudio (01:45 h) 21 jan. 2020.

SANTOS, Rafael Pereira. Da existência ilhada ao território: Estratégias e Trajetórias da Comunidade de Croatá, MG na Busca de Conquistar seu Território. 2019. f. Dissertação (Mestrado em Estudos Rurais) - Departamento de Ciências sociais e Humanidades, Universidade Federal dos Vales do Jequitinhonha e Mucuri, Diamantina, 2019.

SANTOS, Tereza Cordeiro. Entrevista concedida a Roberta Alves. Veredinha, MG: Gravador, áudio (01:07 h) 27 de Jan de 2019.

SAQUET, Marcos Aurélio. Território e territorialidades: teorias, processos e conflitos. São Paulo: Expressão popular, 2009. p. 73-94.

SAYAD, Abdelmalek. A imigração ou os paradoxos da alteridade. Trad. 
Cristina Murachco. São Paulo: Editora da universidade de São Paulo, 1998.

SILVA, Ana Nunes Alves. Entrevista concedida a Roberta Alves. Veredinha, MG: Gravador, áudio (29:14 h) 22 jan. 2020.

SILVA, Geni Nunes da. Entrevista concedida a Roberta Alves. Veredinha, MG: Gravador, áudio (00:59 h) 21 jan. 2020.

SILVA, Maria Aparecida de Moraes. As mulheres das Grotas e Veredas. In: FACCIOLI, Inês et al. Migrantes Temporários Peregrinos da Resistência. São Paulo: Editora serviço Pastoral dos Migrantes - SPM, 1991.

SILVA, Roberta Alves; RECH, André Rodrigo; SANTOS, Rafael Pereira. O Movimento das Vidas no Movimentar das Fronteiras. VI Colóquio Internacional de Povos e Comunidades Tradicionais, Montes Claros, p. 1-12, 2019.

VEIGA, José Eli da. Cidades Imaginárias: o Brasil é menos urbano do que se calcula. Campinas, São Paulo: Editora Autores Associados, 2002. 